\title{
Editorial
}

\section{What's happening in undergraduate medical education?}

Most hospital doctors in the UK will have noticed that something is happening to undergraduate medical education. They may note that students seem to know less of the traditional 'hard science' pre-clinical subjects, but spend more time on 'softer' subjects apparently of doubtful relevance. They may also have been puzzled by a new language: talk of 'aims and objectives', 'formative and summative assessment', 'learning opportunities' and acronyms like 'OSCE'.

Many will ask, since the doctors produced in the past, including themselves, seem satisfactory, why there is this need for change and where has it come from? They may also ask, as good scientists, for the evidence that these new ideas are better. They will, however, find that, unlike other aspects of their work, it is rather difficult to get very satisfactory answers to these questions. It is generally possible for most doctors, faced with a clinical problem and access to a modest medical library and a computer, to find a solution or at least a way forward within a few minutes. In contrast, if they try entering the above terms into a Medline search, the results will disappoint.

The impetus for change in the UK was the publication in December 1993 by the General Medical Council (GMC) of Tomorrow's Doctors. This is a remarkable document and a good starting point for anyone wishing to understand more about the subject. Although its proposals seemed radical or even revolutionary to many, they were in fact no more than ideas which had been current in medical education circles, particularly in the US, Holland and Australia, for some time. Indeed the GMC traced their central message back to its earliest days when in 1863 it had noted "overloading of the curriculum of education .... followed by results injurious to the student", and in 1869 "some limit must be assigned to the amount of knowledge that can be fitly exacted'.

Over 100 years later when little had happened, the patience of the GMC finally gave out and it declared "the Education Committee of the GMC should ensure the implementation of the recommendations .... when necessary by the exercise of the statutory powers given to it under the Medical Acts". It was this implicit threat that recognition of degrees for the purposes of registration could be suspended if action was not taken, which provided the impetus for action.

As well as curricular overload, the GMC identified a number of other imperatives for change. These included increased interest in the health of populations rather than individuals, the move of much medical care to the community, changing patterns of disease, the application of new scientific methods and the increased awareness and expectations of the public in matters relating to health and disease.

Medical schools have for the most part reacted favourably to the recommendations, indeed there has probably been more discussion and debate about medical education in the last 5 years than in the previous 50 . Following the lead of the GMC, the factual burden has been reduced by dividing course into 'core' material which all should know and 'special study modules' where students can pursue learning to a higher level in a smaller range of subjects, often of their own choosing. Although this means that students end up 'all knowing different things', it can work well if the main purpose is not to cram in more knowledge but to demonstrate the scientific method within a particular medical context and then to generalise it to the rest of the course.

Identification of 'core' objectives has largely followed the GMC's guidelines and many universities have concentrated on clinical competency or 'what doctors really need to be able to do'. This generally goes down well with practising clinicians but there may be an anxiety from academics that, in the rush for relevance, students lose some appreciation of the scientific underpinning of the subject. My own view is that if our students' natural curiosity is anything like that of their teachers, they will not be satisfied with a superficial approach.

Tomorrow's Doctors pays particular attention to attitudinal objectives with a list which has been particularly useful for those of us who find such concepts difficult to define. Key to the concept of 'core' is that of 'vertical and horizontal integration'. Vertical integration means ensuring that clinical education informs and is informed by medical science; horizontal integration is about breaking down specialty and departmental barriers. In clinical education much of what a student learns is applicable across all specialties, particularly the skills of history taking, clinical examination, and clinical reasoning.

Setting appropriate objectives is only of value if the learning framework allows students to meet them. The principles of adult learning suggest that students learn best when the objectives are clear and relevant, when they can study at their own pace, when they can build on prior knowledge, and when their learning is supported. Medical education has in the past paid little attention to these. For clinical education the basic framework is the ward, clinic or surgery; structures designed for quite different purposes. Teaching methods are still too often reported by students as working on the principle of humiliation, not always by misogynist male surgeons! Nevertheless the framework for medical education has many advantages, not least the immediate relevance of clinical experience to future practice. Managing the clinical environment to make it more student-friendly should be a major goal of any educational programme.

Assessment methods are crucial to the success of any educational enterprise. We might like to think that our students study for its own sake, but in practice, assessment drives learning. Whatever is stated in the objectives or in lectures or in small group teaching, if it does not appear in the examination it will not be valued by the student and the course will be diminished.

The GMC recognised that assessment methods would need to change, but in practice attempts to change assessment have caused much controversy. No doubt this comes from the determination of many that whatever else may be done to the course, preservation of a traditional examination will be seen to maintain standards. Most controversies in medicine reflect inadequate knowledge, and opinions on assessment systems are no different. Nevertheless, it seems clear that many current systems of clinical assessment are defective. The difficulty is that there is no perfect system, but some systems are rather better than others.

Examinations need to be valid (they test what we want to test) and reliable (they are reproducible). They also need to 
be practicable (capable of being run within the available resources). Clinical examinations have usually involved a combination of essays, multiple choice questions (MCQs), and clinical encounters with patients ('long' and 'short' cases). Essays are good at testing integration of knowledge but can only cover a small part of the course objectives. MCQs are highly reliable but usually only test factual recall. Patient encounters appear valid (they reproduce what doctors do) but it is difficult to test widely without a large increase in resources. Reliability can be low given the variety of patients and examiners.

A number of solutions have been proposed to these problems. Modified Essay Questions typically require short answers to a number of questions based on a clinical scenario. It is possible to have many more such scenarios than would be possible in a traditional essay paper and to test application of knowledge, not just factual recall. Framing the questions requires great care to avoid ambiguity.

Objective Structured Clinical Examinations (OSCEs) have swept the world of medical education in the last decade or so. The usual format is that each student moves round a series of 'stations' every 5 to 10 minutes. At each station they are required to perform a task under observation, such as taking a short history, performing an examination, or undertaking a procedure. The examiners score the performance according to criteria previously agreed. The result is generally valid and reliable but only if large numbers of stations are used. A major strength is that the encounter is fully observed by the examiner. There is the potential to collect much more data than if the student were left alone with the patient to report their findings later. One criticism is that the method tends to treat competence as a series of isolated events rather than as an integrated whole, and future developments will probably centre around attempts to improve OSCEs by lengthening each station so as to test integration and clinical reasoning better. Marking schemes, which have been quite rigid, may be relaxed with the recognition that the reliability of professionals judging professional ability is reasonably high.

How do we know that any of this works? Why should medical schools not run proper controlled trials as they would for a clinical innovation? In fact, there has been considerable educational research into these ideas, although not always in a form easily accessible to doctors. There have been controlled trials in the USA and in Holland comparing cohorts of students in different systems. These suggest that the end product of the new courses is indeed not so very different from the old; students on the new courses were, however, able to make better use of their knowledge and were better lifelong learners. The main benefit, however, seems to be that students enjoy themselves more; perhaps therefore a justification is that anything that increases life's enjoyment may be accounted a Good Thing!

J B COOKSON

Director of Clinical Studies, University of Leicester, Leicester, UK

Accepted 9 February 1999

Keywords: education; learning

The course consists of six Day Schools to take place once a month from Saturday 9 October 1999. Each session involves two lectures; the first providing a historical background and the second considering current issues and practices, with plenty of opportunity for questions and discussion.

Session topics are:

Public Health

Infectious Disease

Diet \& Health

Approaches to Medicine

Pharmacy

Caring for Health

The price for each session is $£ 10$, including free entry to the museum. A discount is available for full attendance if booked in advance.

CME and CPD accreditation is being sought for all sessions.

For further information and a booking form please contact the Thackray Medical Museum, Beckett Street, Leeds, LS9 7LN. Tel: 011324443 43; Fax: 0113247 0219; Email: medical_museum@msn.com 